\title{
SELF-ESTEEM REMAJA PUTRI YANG MENGALAMI OVERWEIGHT DI SMP DHARMA WANITA SURABAYA
}

\author{
Aristina Halawa* \\ STIKes William Booth Surabaya, Jl. Cimanuk No 20, Surabaya 60241. \\ halawaaristina@yahoo.co.id
}

\begin{abstract}
ABSTRAK
Remaja yang mengalami overweight seringkali mengalami masalah harga diri rendah karena merasa bahwa fisik merupakan hal yang sangat peting untuk memiliki teman atau masuk dalam suatu grup.. Self-Esteem atau harga diri yang rendah akan membuat individu merasa malu, memiliki persepsi yang negatif terhadap dirinya dan hal ini akan mempengaruhi remaja tersebut dalam bergaul dan bahkan akan mempengaruhi prestasinya. Tujuan penelitian ini adalah untuk mengetahui gambaran Self-Esteem pada remaja yang mengalami overweight. Penelitian ini menggunakan desain penelitian Deskriptif dengan populasi seluruh siswa di SMP Dharma Wanita Surabaya yaitu ssebanyak 44 responden dengan sampling menggunakan total sampling. Pengumpulan data menggunakan kuisioner, data yang diperoleh kemudian dimasukkan ke dalam tabel distribusi frekuensi. Hasil penelitian dari 44 responden yang mengalami overweight diperoleh hasil 35 siswa (79,55\%) memiliki self-esteem rendah dan 9 siswa $(20,45 \%)$ self-esteem tinggi. Peran orang tua dan sekolah sangat penting untuk membentuk cara pandang remaja kearah yang positif sehingga dapat menerima dirinya apa adanya dan memiliki self esteem yang tinggi.
\end{abstract}

\section{Kata Kunci: Self-Esteem, Overweight, Remaja}

\begin{abstract}
Adolescents who are overweight often experience low self-esteem problems because they feel that physicality is very important to have friends or be in a group. Self-esteem or low self-esteem will make individuals feel embarrassed, have negative perceptions of themselves and this will affect the adolescent in socializing and will even affect their performance. The purpose of this study was to determine the description of Self-Esteem in adolescents who are overweight. This study used a descriptive research design with a population of all students at SMP Dharma Wanita Surabaya, namely 44 respondents with sampling using total sampling. Data collection using a questionnaire, the data obtained is then entered into a frequency distribution table. The results of the study of 44 respondents who were overweight showed that 35 students $(79.55 \%)$ had low self-esteem and 9 students $(20.45 \%)$ had high self-esteem. The role of parents and school is very important to form a positive perspective of adolescents so that they can accept themselves as they are and have high self-esteem.
\end{abstract}

\section{Keywords: Self-Esteem, Overweight, Adolescents}




\section{PENDAHULUAN}

Istilah remaja sering disamakan dengan istilah adolescene, yaitu suatu keadaan yang menggambarkan suatu periode perubahan psikososial yang menyertai pubertas (Soetjiningsih, 2012). Adolescene merupakan istilah yang memiliki arti yang luas yang menyangkup kematangan mental, sosial, emosional dan fisik (Hurlock,2010). Pada masa ini terjadi transisi perubahan fisik dan psikis, yang melibatkan pada kebanyakan remaja putri memiliki peningkatan atau perfoma fisik seperti halnya dengan memiliki perubahan tinggi badan, kekuatan, dan berat badan yang semakain bertambah atau overweight. Hal ini juga dapat menimbulkan respon tersendiri bagi remaja putri yang mempunyai gangguan berupa gambaran diri atau tingkah laku yang sangat memfokuskan dirinya untuk lebih memperhatikan bentuk tubuhnya. Penampilan juga sangat dianggap penting dan utama bagi seseorang remaja putri sehingga bentuk tubuh yang tidak ideal seperti terlalu gemuk, terlalu kurus akan membuat remaja putri kerap memiliki rasa ketidakpuasan dirinya terhadap keadaan fisiknya (Wati, 2017). Menurut hasil penelitian Ayu Solistiawati, Novendawati mengenai "Hubungan antara citra tubuh dengan harga diri remaja akhir putri studi pada mahasiswi reguler universitas esa unggul" hasil penelitian menunjukkan bahwa selama masa masa remaja putri mulai banyak mengalami perubahan tubuh pubertas dengan $24-26 \%$ responden pada remaja putri kerap memiliki ketidakpuasan pada tubuhnya dan citra tubuh pada remaja putri tersebut menjadi negatif karena berat badan berlebih (overweight). Pada umumnya bentuk tubuh yang berlebih atau overweight sangatlah mengganggu remaja. Banyak usaha yang dilakukan para remaja putri untuk membentuk tubuhnya menjadi ideal, seperti menggunakan pakaian dengan warna yang gelap dan menambahkan shapewer/stagen untuk menutupi bagian tubuh yang terlihat berlemak. hal itu dilakukan remaja putri agar dapat memiliki tubuh yang menarik, karena bila pada remaja putri merasa bahwa tubuhnya tidak ideal, biasanya remaja putri mudah sekali tersinggung dan mudah marah (Rudystina, 2017). Remaja putri yang mengalami gangguan body image juga memiliki masalah dengan selfesteem. Remaja yang memiliki self-esteem negativ akan merasakan bahwa teman temannya sedang membandingbandingkan serta membicarakan tubuhnya dan berpendapat bahwa wanita cantik itu harus bertubuh langsing (Hurlock, 2010). Setiap perkataan atau ungkapan teman temannya, sangatlah berpengaruh pada psikologis pada remaja putri tersebut, seperti malu untuk mulai mengawali pembicaraan dengan teman-temannya dan tidak memiliki keberanian untuk mengungkapkan perkataan atau masukan di depan orang banyak, sering duduk menyendiri dan susah untuk bersosialisasi dengan teman temannya (Sari, Permata 2012). Data ini juga didukung saat penulis berkunjung di SMP Dharma Wanita Surabaya dan saat penulis mengamati ada sebagian remaja putri yang memiliki berat badan overweight sedang duduk menyendiri dibangku depan kelasnya karena malu, sedangkan di samping remaja tersebut terlihat banyak remaja putri yang asik bermain.

Berdasarkan badan pusat statistik (2015) menyatakan bahwa jumlah remaja usia 10-15 Tahun di provinsi Jawa Timur mencapai 3.046.481 jiwa yang terbagi menjadi 1.490 .163 perempuan dan 1.556.318 laki-laki. Selanjutnya berdasarkan badan penelitian \& Pengembangan kesehatan RI Tahun (2013), Menyatakan bahwa pada remaja usia 13-15 tahun yang prevalensi remaja memiliki berat badan berlebih adalah 
$10,8 \%$ yang terdiri dari $8,3 \%$ overweight dan 2,5\% obesitas. Prevalensi nasional tersebut pada umumnya perempuan lebih tinggi dari pada laki-laki yaitu $32,9 \%$ dibandingkan 19,7\%. Dari presentasi tersebut cukup menjadi masalah untuk terjadinya overweight dan obesitas. Karena data ini lebih tinggi dibandingkan dengan data Riset kesehatan dasar (2014) Nasional yang prevalensi status gizi overweight sebesar $8,9 \%$ dan status gizi obesitas sebesar 3,0\%. Sedangkan status gizi remaja di Surabaya berdasarkan IMT/U diketahui status gizi kurus sebesar 7,8\%, status gizi normal sebesar 76,3\%, status overweight sebesar $8,9 \%$ dan status obesitas sebesar 3,9\%. Berdasarkan survey pendahuluan yang peneliti lakukan di sekolah SMP Dharma Wanita Surabaya terdapat 15 siswa dari kelas VII-A yang memiliki berat badan lebih (overweight) dan pada saat penulis mengkaji tentang bagaimana respon mereka terhadap kondii overweight yang mereka alami terdapat 4 remaja yang memiliki Self-esteem rendah atau negatif. Sikap elf esteem yang rendah ini mereka ungkapkan bahwa remaja putri tersebut malu untuk tampil di depan umum dan berbicara di depan teman temannya.

Pada era moderen saat ini, remaja banyak yang menyukai makanan cepat saji seperti fast food dan mie instan, terkhususnya pada remaja putri yang mempunyai selera makan yang tinggi, seringkali pada remaja putri saat dirinya sedang stres atau banyak fikiran cenderung pada remaja putri memilih mengkonsumsi makanan makanan yang mempunyai kalori dan kolesterol tinggi, dan remaja putri tersebut kurang melakukan aktifitas fisik seperti melakukan olahraga (Nindya, Hanifah. 2012). Sehingga dari kebiasaankebiasaan tersebut dapat membuat remaja putri mengalami peningkatan berat badan, jika pada remaja putri memiliki body image yang baik, maka dirinya tersebut akan menerima keadaan tubuhnya dengan mengubah kebiasaan pola makan seperti mengurangi makanan fast food dan tidak makan terburu buru, dan tidak mudah tersinggung terhadap perkataan orang lain, serta tetap bergabung dengan teman temannya. keadaan tersebut menandakan bahwa harga dirinya tetap baik dan memiliki kepercayaan yang baik, tetapi jika dirinya tidak memiliki body image yang baik maka dirinya akan merasa tidak siap menerima keadaan tubuhnya sehingga dia melakukan upaya seperti memilih diet secara ekstrim, menutupi bagian-bagian tubuhnya yang terlihat berlemak dengan menggunakan pakaian yang ketat, mudah tersinggung sehingga dirinya mulai menjauhkan diri dari teman-temannya, serta perilaku-perilaku negatif tersebut dapat mempengaruhi remaja putri didalam lingkungan sekolah, seperti mengalami penurunan didalam prestasi belajarnya sehingga menyebabkan remaja tersebut tinggal kelas, sehingga dia merasa sedih dan putus asa serta enggan untuk melanjutkan pendidikannya. Seringkali pada remaja melakukan hal yang dapat menenangkan dirinya, bisa mengarah kedalam hal negatif misalnya penyalahgunaan narkoba, minum obatobatan yang terlarang dan sampai mempunyai keinginan untuk bunuh diri. Keadaan tersebut menandakan bahwa harga dirinya tidak baik dan remaja putri tidak memiliki kepercayaan yang baik.

Remaja putri diharapkan dapat menerima dirinya apa adanya dengan cara memperbaiki kepercayaan diri dengan menghilangkan pikiran-pikiran negatif dan menganggap bahwa orang lain juga merasa nyaman dengan kita, dengan itu mulailah tumbuhkan sikap positif dengan menerima kekurangan dan kelebihan diri sendiri dengan menguatkan emosi saat menghadapi orang lain seperti mempertahankan hubungan antara perasaan, pikiran serta keinginan kita untuk berbagi pengalaman dengan orang lain, dengan tumbuhkan sikap positif dengan bersosialisasi dengan orang lain, maka hal itu akan mempermdah kita untuk merasa nyaman dengan diri sendiri serta dengan begitu mereka akan memberi dukungan terhadap diri kita untuk lebih 
mencintai diri kita sendiri (Stuart dan Sundeen, 1991). Remaja Putri yang mengalami masalah harga diri dapat ditingkatkan dengan cara G-R-O-W-T-H yaitu 1) Goal setting dengan Merencanakan tujuan, 2) Risk taking dengan mengambil resiko, 3) Opening up dengan membuka diri, 4) Wisechoice making dengan membuat keputusan yang bijaksana, 5) Time sharing dengan berjalan sesuai dengan waktu, 6) Healing dengan penyembuhan, (Lerner \& Hultsch, 2003). Dengan menerapkan hal tersebut remaja putri akan dapat mengembalikan harga dirinya atau Self-esteem dengan menentukan tujuan hidup yang ingin dicapai dengan dibutuhkan usaha dan keinginan yang kuat (ambisi) untuk dapat mencapai khusunya dalam belajar dan meraih prestasi. Remaja putrid yang overweight harus berani mengambil resiko untuk memenuhi dan mencapai tujuannya, dengan membuka diri dan bisa berbagi rasa dengan orang lain dengan membuat keputusan yang benar dan bijaksana, jangan terlalu memberikan tekanan atau paksaan pada diri sendiri. Hal ini sesuai dengan yang disampaikan Iyus Yoseph (2007) alangkah baiknya remaja mampu memacu diri sendiri lebih optimis dan cenderung berambisi tinggi dalam mencapai aspek kehidupan baik secara emosional dan mampu menjalin hubungan baik dengan orang lain. Remaja Putri yang overweight diharapkan dapat menerima dirinya apa dirinya lalu menerapkan tujuan yang ingin dicapai sesuai kemampuannya sehingga bila mencapai keberhasilan hal ini akan meningkatkan self esteem remaja tersebut.

\section{METODE}

Berdasarkan tujuan penelitian, desain penelitian yang digunakan dalam penelitian ini adalah deskripstif yatu metode penelitian yang bertujuan untuk menjelaskan, memberi suatu nama, situasi atau fenomena dalam menemukan ide baru (Nursalam, 2003).

Penelitian ini bertujuan untuk mengetahui gambaran self Esteem remaja putri yang mengalami overweight di SMP Dharma wanita Surabaya yaitu sebanyak 44 remaja.

Sampel dalam penelitian ini adalah seluruh remaja putri yang mengalami overweight di SMP Dharma wanita Surabaya yaitu sebanyak 44 remaja dengan teknik sampling yang dipergunakan yaitu total sampling.

Pengambilan data tentang self Esteem remaja putri yang mengalami overweight di SMP Dharma wanita Surabaya dilakukan dengan menyebarkan kuisioner tentang Self esteem kepada responden setelah menandatangani lembar informed consent. Cara menilai tingkat self Esteem remaja putri yang mengalami overweight di SMP Dharma wanita Surabaya kuesioner terdiri dari 10 pertayaan. Penilaian untuk pernyataan positif sangat setuju $=4$, setuju $=3$, tidak setuju $=2$, dan sangat tidak setuju $=1$ dan untuk pernyataan negative sangat setuju $=$ 1 , setuju $=2$, tidak setuju $=3$, sangat tidak setuju $=4$.

\section{HASIL DAN PEMBAHASAN}

\section{Responden Berdasarkan Usia}

Tabel 1. Karakteristik responden berdasarkan Usia di SMP Dharma Wanita Surabaya

\begin{tabular}{llll}
\hline No. & Usia & $\begin{array}{l}\text { Jumlah } \\
\text { (f) }\end{array}$ & $\begin{array}{l}\text { Presentase } \\
(\%)\end{array}$ \\
\hline 1 & 10 tahun & 0 & 0 \\
\hline 2 & 11 tahun & 8 & 18,18 \\
\hline 3 & 12 tahun & 24 & 54,54 \\
\hline 4 & 13 tahun & 12 & 27,28 \\
\hline & Total & 44 & 100,00 \\
\hline & Berdasarkan & Tabel & 1 dapat
\end{tabular}

diketahui bahwa responden yang berusia 12 tahun merupakan responden terbanyak dengan jumlah 24 siswa ( 54,54\%).

\section{Responden berdasarkan Urutan anak dalam keluarga}


Tabel 2 Karakteristik responden berdasarkan urutan anak dalam keluarga di SMP Dharma Wanita Surabaya

\begin{tabular}{llll}
\hline No. & $\begin{array}{l}\text { Urutan } \\
\text { anak } \\
\text { dalam } \\
\text { keluarga ( } \\
\text { Anak ke-) }\end{array}$ & $\begin{array}{l}\text { (f) } \\
(\%)\end{array}$ \\
\hline 1 & 1 & 22 & 50 \\
\hline 2 & 2 & 18 & 40,91 \\
\hline 3 & 3 & 4 & 9,09 \\
\hline 4 & 4 & 0 & 0 \\
\hline & Total & 44 & 100,00 \\
\hline
\end{tabular}

Berdasarkan tabel 2 dapat diketahui bahwa responden yang merupakan anak pertama dalam keluarga merupakan responden terbanyak dengan jumlah 22 siswa (50\%).

\section{Responden berdasarkan jumlah saudara dalam keluarga}

Tabel 3 Karakteristik responden berdasarkan jumlah saudara dalam keluarga di SMP Dharma Wanita Surabaya

\begin{tabular}{llll}
\hline No. & $\begin{array}{l}\text { Jumlah } \\
\text { Sodara } \\
\text { dalam } \\
\text { Keluarga }\end{array}$ & $\begin{array}{l}\text { Jumlah } \\
\text { (f) }\end{array}$ & $\begin{array}{l}\text { Presentase } \\
(\%)\end{array}$ \\
\hline 1 & 1 & 7 & 15,91 \\
\hline 2 & 2 & 16 & 36,36 \\
\hline 3 & 3 & 17 & 38,64 \\
\hline 4 & 4 & 4 & 9,09 \\
\hline & Total & 44 & 100,00 \\
\hline
\end{tabular}

Berdasarkan tabel 3 dapat diketahui bahwa jumlah saudara responden terbanyak adalah 3 saudara dengan jumlah 17 siswa $(36,64 \%)$.

\section{Responden berdasarkan pendidikan orang tua}

Tabel 4 Karakteristik responden berdasarkan pendidikan orang tua siswa di SMP Dharma Wanita Surabaya.

No. Pendidikan Jumlah Presentase

\begin{tabular}{llll}
\hline & orang tua & $(\mathrm{f})$ & $(\%)$ \\
\hline 1 & SD & 6 & 13,64 \\
\hline 2 & SMP & 8 & 18,18 \\
\hline 3 & SMA & 17 & 38,64 \\
\hline 4 & Diploma & 13 & 29,54 \\
\hline & Total & 44 & 100,00 \\
\hline
\end{tabular}

Berdasarkan tabel 4 dapat diketahui bahwa jumlah pendidikan orang tua siswa tebanyak adalah pendidikan SMA sebanyak $17(38,64 \%)$.

\section{Responden berdasarkan pekerjaan} orang tua

Tabel 5 Karakteristik responden berdasarkan pekerjaan orang tua siswa di SMP Dharma Wanita Surabaya

\begin{tabular}{llll}
\hline No & $\begin{array}{l}\text { Pekerjaan } \\
\text { Orang Tua }\end{array}$ & $\begin{array}{l}\text { Jumlah } \\
\text { (f) }\end{array}$ & $\begin{array}{l}\text { Persentase } \\
(\%)\end{array}$ \\
\hline 1 & Swasta & 22 & 50 \\
\hline 2 & Wiraswasta & 16 & 36,36 \\
\hline 3 & PNS & 3 & 6,82 \\
\hline 4 & Tidak Bekerja & 3 & 6,82 \\
\hline & Total & 44 & 100,00 \\
\hline
\end{tabular}

Berdasarkan tabel 5.5 dapat diketahui bahwa jumlah pekerjaan orang tua siswa tebanyak adalah pekerjaan Swasta sebanyak $22(50 \%)$.

Responden berdasarkan pengasuh siswa

Tabel 6 Karakteristik responden berdasarkan pengasuh siswa di SMP Dharma Wanita Surabaya.

\begin{tabular}{llll}
\hline No & Pengasuh & $\begin{array}{l}\text { Jumlah } \\
\text { (f) }\end{array}$ & $\begin{array}{l}\text { Persentase } \\
(\%)\end{array}$ \\
\hline 1 & Orang Tua & 28 & 63,64 \\
\hline 2 & Nenek/Kakek & 14 & 31,82 \\
\hline 3 & Pembantu & 0 & 0 \\
\hline 4 & Lain Lain & 2 & 4,54 \\
\hline & Total & 44 & 100,00 \\
\hline
\end{tabular}

Berdasarkan tabel 6 dapat diketahui bahwa jumlah pengasuh siswa sebagian besar adalah diasuh oleh orang tua sebanyak 28 $(63,64 \%)$.

\section{Karakteristik Self-Esteem}


Tabel 7 Karakteristik Self-Esteem remaja putri yang overweightdi SMP Dharma Wanita Surabaya.

\begin{tabular}{llll}
\hline No & Self-Esteem & $\begin{array}{l}\text { Jumlah } \\
\text { (f) }\end{array}$ & $\begin{array}{l}\text { Persentase } \\
(\%)\end{array}$ \\
\hline 1 & Tinggi & 9 & 20,45 \\
\hline 2 & Rendah & 35 & 79,55 \\
\hline & Total & 44 & 100,00 \\
\hline
\end{tabular}

Berdasarkan tabel 7 dapat diketahui bahwa Self-Esteem siswa tebanyak adalah mayoritas memiliki Self-Esteem Rendah sebanyak $35(79,55 \%)$.

\section{PEMBAHASAN}

Berdasarkan tabel 7 dapat dilihat dari 44 responden terdapat 35 remaja putri $(79,55 \%)$ memiliki Self-esteem rendah dan pada 9 remaja putri $(20,45 \%)$ memiliki self-esteem tinggi. Hal ini terbukti bahwa remaja putri yang mengalami overweight di SMP Dharma Wanita Surabaya banyak yang mengalami self-esteem rendah. Menurut Santrock, (2007) Sebagian remaja putri memiliki self-esteem rendah dikarenakan oleh berbagai macam karakter individu, seperti pada remaja putri seringkali dirinya merasa diasingkan dan merasa tidak diperhatikan oleh teman sebayanya sehingga remaja mengalami harga diri rendah karena anak mengalami kegagalan didalam menghadapi masalah sehingga anak lebih memilih menghindari dari pada mengatasinya. Sebaliknya menurut Suhron (2017) mengatakan bahwa harga diri rendah akan terjadi jika adanya tekanan dari orang sekitar yang akan mengakibatkan remaja merasa takut akan ketidakmampuan menghadapi kenyataan yang ia terimanya. Ketika ia sedang berinteraksi dengan teman sebayanya, ia selalu memfokuskan diri untuk melihat penampilan fisik temantemannya yang lain. Novendawati, Solistiawati (2015) mengatakan bahwa rendahnya self-esteem pada remaja putri dipengaruhi oleh beberapa faktor salah satunya adalah usia. Dimana self-esteem pada rentan usia remaja awal akan mengalami perubahan psikologis yang membuat self-esteem mereka menjadi rendah. Pada remaja awal terjadi perubahan pada fase perkembangan antara masa anak-anak menuju dewasa. Dimana pada fase ini ditandai oleh perubahan fisik, emosional yang tidak stabil,serta seksual dan sosial yang tidak mendukung kondisi mereka sehingga berakibat pada rendahnya harga diri remaja tersebut. Seperti pada tugas perkembangan remaja menurut Agustiani (2006) mengatakan bahwa seorang remaja harus bisa menerima kenyataan terjadinya perubahan fisik pada dirinya dan tetap dapat melakukan perannya sesuai kondisi fisiknya secara efektif dan merasa puas terhadap semua keadaan yang ia miliki. mengingat tugas-tugas perkembangan remaja sangatlah kompleks, maka untuk dapat melaksanakan tugas-tugas tersebut dengan baik, remaja sangat membutuhkan bimbingan dan pengarahan supaya dapat mengambil langkah yang tepat sesuai dengan kondisinya. Hal ini sesuia dengan yang disampaikan oleh Edward bahwa kebutuhan remaja itu adalah meliputi 1)kebutuhan untuk mencapai sesuatu, 2)kebutuhan akan superior, ingin menonjol, 3) kebutuhan untuk mendapatkan penghargaan. Bila dilihat pada hasil gambaran umum pada tabel 1 dimana remaja putri yang mengalami overweight sebagian besar berusia 12 tahun yaitu sebanyak 24 responden sebesar $(54,54 \%)$, hal ini mendukung hasil penelitian ini dimana sebagian besar remaja mengalami harga diri rendah. Dari hasil ini menunjukkan bahwa sebagian besar remaja putri di SMP Dharma wanita baru memasuki remaja awal dimana banyak sekali perubahan didalam diri mereka baik fisik, psikis dan emosi yang membuat mereka sulit memiliki pandangan yang posistif bila tidak sama dengan 
temanya. Mereka mempunyai cara pandang yang salah terhadap penampilan fisiknya karena dalam pergaulannya mereka selalu beranggapan jika ia akan dikucilkan oleh teman-temannya yang lain karena memiliki berat badan berlebih sehingga remaja tersebut memiliki rasa malu, canggung, dan tidak mampu mengekspresikan diri saat berinteraksi dengan orang lain. Selain itu ia juga belum cukup matang untuk mempresepsikan penampilan fisiknya, sehingga remaja cenderung lebih pesimis, sinis dan memiliki pikiran yang tidak fleksibel. serta dapat disimpulkan bahwa seseorang remaja putri yang memasuki masa transisi seringkali remaja tersebut cenderung masih lebih suka menggunakan banyak teknik untuk memperhatikan diri sendiri (defense mechanism) serta masih memiliki perasaan inferior.

Pada data yang didapatkan orang tua responden mempunyai pendidikan terakhir SMA sebanyak 17 siswa $(38,64 \%)$, yang menunjukkan bahwa pendidan orang tua pada dasarnya sudah baik. Dengan pendidikan orang tua yang tinggi diharapkan orang tua mampu berperan dalam meningkatkan harga diri pada anak dengan cara membimbing dan mengarahkan nak agar selalu memiliki pemikira yang positif dan menerima diri apa adanya karena setiap orang adalah unik sehingga anak tidak mengalami selfesteem yang rendah. Namun dalam penelitian ini remaja memiliki self-esteem rendah karena mungkin orang tua kurang memperhatikan hal ini karena orang tua menganggap itu hal yang biasa dan dengan sendirinya nanti akan berubah, padahal dalam kondisi seperti ini penting sekali memperhatikan dan memberi penghargaan kepada anak sehingga mereka memiiki self-esteem yang tinggi. Menjelang masa remaja, anak mengalami kondisi dimana kehidupan terasa bebas, rasa penasaran tinggi terhadap hal-hal baru. Disini peran orang tua menjadi sangat lebih penting terutama sebagai agen of control bagi perilaku remaja. Menurut Sahri (2016) orang tua beranggapan anak merupakan masa depan bagi orang tua, sehingga anak harus memperoleh pendidikan yang disesuaikan dengan potensinya, dan dengan begitu seorang remaja dapat tumbuh dan berkembang secara optimal. Jika pendidikan orang tua semakin tinggi, maka orang tua mampu memberikan pola asuh baik kepada remaja seperti peran orang tua untuk mendorong remaja putri yang mempunyai berat badan overweight sebaiknya harus bisa saling menjalin komunikasi dua arah yang baik, seperti memberi motivasi, dan memberi kesempatan kepada anak untuk bercerita dan mencurahkan isi hatinya. Dengan demikian remaja merasa memiliki temn dan tidak perlu takut bila ada yang tidak menerima dirinya karena memiliki berat badan yang lebih sehingga anak dapat bertumbuh dan berkembang dengan baik serta dapat mencapai cita cita mereka dengan baik yang juga sesuai dengan harapan orang tua mereka. Remaja yang memiliki berat badan berlebih biasanya memiliki harga diri yang rendah karena mereka mendapatkan tekanan dari teman temannya dan apabila orang tua dapat memahami apa yang remaja inginkan mengenai penampilan fisik mereka dan dapat memotivasi remaja agar menerima diri apa adanya maka remaja putrid yang overweight tersebut akan memiliki selfesteem yang tinggi.

\section{SIMPULAN}

Berdasarkan penelitian yang telah dilakukan maka dapat disimpulkan sebagai berikut : Self-efficacy putri yang overweight di SMP Dharma Wanita Surabaya mayoritas responden memiliki Self-esteem rendah sebanyak 35 remaja putri $(79,55 \%)$.

\section{SARAN}

Dengan adanya penelitian ini diharapkan meningkatkan peran 
bimbingan konseling dalam upaya menggali potensi dan bakat yang dimiliki masing-masing siswa melalui pendekatan pada siswi yang masih mengalami selfesteem rendah. Selain itu dapat melakukan kegiatan kegiatan yang positif sehingga remaja memiliki jati diri diri yang kuat.

\section{DAFTAR PUSTAKA}

Agustiani, Hendrianti, 2006. Psikologi Perkembangan. Jakarta: Prefika Aditama http://Organisasi.Org/rumusmenghitung-berat-badan-idealnormal-indeks-broca-brocaindex.www.google.com

Hurlock, 2006. Perubahan pertumbuhan pada remaja. Jakarta : Rineka Cipta

Hurlock, Elizabeth, 2003. Psikologi Perkembangan. Jakarta: Erlangga.

Lerner \& Hultsch, 2003. Perkembangan Remaja. Jakarta : Rineka Cipta

Nindya, Hanifah. 2012. Hubungan Kontribusi beban Glikemik makanan dan aktivitas fisik terhadap kejadiann gizi lebih pada remaja di SMP Full Day Surabaya. Diunduh http://www.google.com

Novendawati, Solistiawati. 2015.

Hubungan Antara Citra Tubuh Dengan Harga Diri Remaja akhir Putri Studi pada Mahasiswa Reguler Universitas Esa Unggul. Diunduh http://www.google.com

Nursalam, 2003. Pendekatan Praktis Metodelogi Riset Keperawatan. Jakarta : CV. Agung Seto
Rudystina, Adinda.2017 Kiat Menerima Kekurangan Diri dan Membangun Body Image Positif. Diunduh http://www.google.com/url?sa=t\&so urce=web\&rct=j\&url=https://hellose hat.com/hidupsehat/psikologi/menerimakekurangan-diri-membangun-bodyimage-citra-diripositif/amp/\&ved=2ahUKEwjyqNq 3h17gAhUHr48KHdurBAoQFjAKe gQIBhAB\&usg=AOvVaw1JoUQiH aBKG8i4RvYHwb3b\&ampcf=1

Sari, Permata. 2012. Hubungan antara Body Image dengan Self-Esteem pada Dewasa Awal Tuna Daksa. Diunduh http://www.google.com

Sahri, Narotama, Firda. 2016. Hubungan antara body image dengan selfesteem pada wanita dewasa awal pengguna skincare. Diunduh http://www.google.com tanggal 1 Januari 2019.

Santrock, John W. (2007). Perkembangan Remaja. Alih Bahasa: Shinto B. Adelar dan Sherly Saragih. Jakarta: Penerbit Erlangga

Soetjiningsih. 2012. Perkembangan Anak dan Permasalahannya dalam Buku Ajar I Ilmu Perkembangan Anak Dan Remaja. Jakarta :Sagungseto

Stuart dan Sundeen. (1998). Buku Saku Keperawatan Jiwa Edisi 3 alih bahasa Achir Yani. S. Jakarta: EGC

Suhron, Muhammad, Ns. 2017. Asuhan keperawatan jiwa konsep selfesteem. Jakarta: Mitra Wacana Media. 
Suliswati, dkk. 2002. Konsep dasar keperawatan kesehatan jiwa. Jakarta: EGC

Wati, Sumarmi. 2017. Citra Tubuh Pada Remaja Perempuan Gemuk dan Tidak Gemuk. Diunduh http://www.google.com

WHO.2003.Adolescene Mental Health Promotion. New Delhi : South East Asia Regional Office of the World Health Organization

Yosep, Iyus. 2007. Keperawatan Jiwa.

Bandung: Refika Aditama. 